\title{
Significance of urinary fatty acid-binding protein 4 level as a possible biomarker for the identification of minimal change disease in patents with nephrotic-range proteinuria
}

Marenao Tanaka ${ }^{1 \dagger}$, Masato Furuhashi ${ }^{1 *+} \mathbb{D}$, Norihito Moniwa', Takuto Maeda², Hideki Takizawa², Megumi Matsumoto ${ }^{1}$, Akiko Sakai ${ }^{1}$, Yukimura Higashiura', Yufu Gocho ${ }^{1}$, Masayuki Koyama', Yayoi Ogawa ${ }^{3}$ and Tetsuji Miura ${ }^{1}$

\begin{abstract}
Background: Fatty acid-binding protein 4 (FABP4), but not FABP1 (liver-type FABP), is ectopically induced in injured glomerular endothelial cells, and urinary FABP4 (U-FABP4) level is associated with proteinuria and renal dysfunction in a general population.

Methods: The clinical significance of U-FABP4 was investigated in 81 patients (male/female: 43/38, age: $57 \pm 17$ years) who underwent kidney biopsy.

Results: U-FABP4 was negatively correlated with estimated glomerular filtration rate (eGFR) $(r=-0.56, P<0.01)$ and was positively correlated with age, blood pressure, triglycerides, proteinuria $(r=0.58, P<0.01)$, plasma FABP4 and urinary FABP1 (U-FABP1) $(r=0.52, P<0.01)$. Multivariable regression analysis showed that eGFR, proteinuria and $U$ FABP1 were independent predictors of U-FABP4. The level of U-FABP4, but not that of proteinuria, eGFR or UFABP1, in minimal change nephrotic syndrome (MCNS) was significantly lower than the level in membranous nephropathy (MN) and that in diabetic nephropathy. Receiver operating characteristic curve analysis indicated that U-FABP4 level $\leq 0.78 \mu \mathrm{g} / \mathrm{gCr}$ predicted MCNS in patients who had nephrotic-range proteinuria with a high level of accuracy. When divided by the median value of U-FABP4 at baseline in 33 of the 81 patients who could be followed up, the yearly change (post-pre) in eGFR in the low U-FABP4 group was significantly greater than that in the high U-FABP4 group (median: 11.0 vs. $-5.0 \mathrm{~mL} / \mathrm{min} / 1.73 \mathrm{~m}^{2} /$ year).

(Continued on next page)
\end{abstract}

\footnotetext{
* Correspondence: furuhasi@sapmed.ac.jp

${ }^{\dagger}$ Marenao Tanaka and Masato Furuhashi contributed equally to this work.

'Department of Cardiovascular, Renal and Metabolic Medicine, Sapporo

Medical University School of Medicine, S-1, W-16, Chuo-ku, Sapporo

060-8543, Japan

Full list of author information is available at the end of the article
}

(c) The Author(s). 2020 Open Access This article is licensed under a Creative Commons Attribution 4.0 International License, which permits use, sharing, adaptation, distribution and reproduction in any medium or format, as long as you give appropriate credit to the original author(s) and the source, provide a link to the Creative Commons licence, and indicate if changes were made. The images or other third party material in this article are included in the article's Creative Commons licence, unless indicated otherwise in a credit line to the material. If material is not included in the article's Creative Commons licence and your intended use is not permitted by statutory regulation or exceeds the permitted use, you will need to obtain permission directly from the copyright holder. To view a copy of this licence, visit http://creativecommons.org/licenses/by/4.0/ The Creative Commons Public Domain Dedication waiver (http://creativecommons.org/publicdomain/zero/1.0/) applies to the data made available in this article, unless otherwise stated in a credit line to the data. 
(Continued from previous page)

Conclusions: U-FABP4 level is independently associated with proteinuria and renal dysfunction in patients with glomerular kidney disease. A low U-FABP4 level may predict MCNS in patients with nephrotic syndrome and would be a useful biomarker for differential diagnosis of MCNS and MN, which are common causes of nephrotic syndrome.

Keywords: Fatty acid-binding protein, Nephrotic syndrome, Membranous nephropathy, Minor glomerular abnormalities, Kidney biopsy

\section{Background}

Chronic kidney disease (CKD) and metabolic syndrome are critical issues against healthy longevity. Therefore, much attention has been paid to the associations between CKD and metabolic disorders including insulin resistance and dyslipidemia [1,2]. Prevention and early diagnosis of CKD are important to avoid renal replacement therapy or kidney transplant, which is required in the end stage of CKD. Furthermore, even in the early stage, CKD is a risk factor for cardiovascular disease in association with metabolic diseases [3]. However, reliable biomarkers for the detection of glomerular damage at an early stage have not been developed yet [4].

The etiology needs to be determined in each case of nephrotic syndrome for selection of therapy since the response to treatment differs depending on the glomerular kidney disease. Several clinical markers, including selectivity index [5], urinary podocytes [6] and M-type phospholipase A2 receptor (PLA2R) [7], have been proposed to predict the etiology of nephrotic syndrome. It has been reported that the circulating level of anti-PLA2R antibodies is useful for diagnosis of idiopathic membranous nephropathy (MN) [7-9], but the sensitivity for diagnosis was reported to be relatively low (53\%) in Japan [10]. Differential diagnosis without kidney biopsy for minimal change nephrotic syndrome (MCNS) and MN, common causes of nephrotic syndrome, is often difficult since urine findings are quite similar, i.e., urinary sediments contain little occult blood [11]. Therefore, the development of predictive markers for differential diagnosis of MCNS and MN is needed.

Fatty acid-binding proteins (FABPs), a family of intracellular lipid chaperones, are proteins of about $14-15 \mathrm{kDa}$ in size that can reversibly bind to hydrophobic ligands, such as long chain fatty acids, with a high affinity and coordinate lipid responses in cells [12-15]. At least 9 different FABPs have been identified, and it has been shown that tissue-specifically expressed FABPs are secreted in various pathological conditions or leak out of cells due to cellular damage $[12,13]$. Among FABPs, FABP1, known as livertype FABP (L-FABP), is expressed in proximal tubular epithelial cells in the kidney, and this FABP isoform in urine has been reported to reflect damage of proximal tubular epithelial cells $[16,17]$.

FABP4, known as adipocyte FABP (A-FABP) or aP2, is expressed in both adipocytes and macrophages and contributes to the development of insulin resistance and atherosclerosis [12, 13, 18-20]. Interestingly, it has recently been reported that FABP4 is also expressed in some vascular endothelial cells [13]. In the kidney, FABP4 is expressed in endothelial cells of peritubular capillaries and veins, but not arteries or glomerular capillaries, in a normal condition [21]. We previously demonstrated that expression of FABP4 was ectopically induced by glomerular injury in cells of the glomerulus, including glomerular endothelial cells and macrophages, and that the extent of ectopic FABP4 expression was closely associated with proteinuria and renal dysfunction [22]. We also revealed in a population-based study that excretion of urinary FABP4 (U-FABP4) is associated with albuminuria and possibly predicts a yearly decline of estimated glomerular filtration rate (eGFR), suggesting that U-FABP4 would be a novel biomarker of glomerular damage [23]. However, excretion of U-FABP4 has not been examined in a study population with kidney diseases diagnosed by biopsy. Therefore, we investigated the associations between U-FABP4 level and clinical characteristics using data for a cohort of patients in whom kidney biopsies were performed.

\section{Methods}

This study conformed to the principles outlined in the Declaration of Helsinki and was performed with the approval of the institutional ethical committee of Sapporo Medical University (number: 28-2-58) and Teine Keijinkai Hospital (number: 2017-031). The present study was separately designed from a previous study [22], in which renal expression of FABP4 in kidney biopsy samples was investigated, and did not include patients who were enrolled in the previous study. Written informed consent was obtained from all of the study subjects.

\section{Study subjects and clinical measurements}

A total of 87 consecutive patients (male/female: 47/40) who underwent kidney biopsy in Teine Keijinkai Hospital during the period from November 2013 to April 2015 were enrolled. Samples of blood and urine were obtained before kidney biopsy during hospitalization. Six patients were excluded because volumes of stored urine samples were insufficient for analysis. After the exclusion, 81 subjects (male/female: $43 / 38$, age: $57 \pm 17$ years) were finally 
recruited in the present study. Most of the patients returned to client hospitals after kidney biopsy for routine management, and 33 of the patients underwent follow-up examination 1 year after the biopsy in Teine Keijinkai Hospital.

eGFR was calculated by an equation for Japanese: eGFR $\left(\mathrm{mL} / \mathrm{min} / 1.73 \mathrm{~m}^{2}\right)=194 \times \mathrm{Cr}^{(-1.094)} \times \operatorname{age}^{(-0.287)} \times$ 0.739 (if female). Level of proteinuria was quantified as protein-to-creatinine ratio in urine $(\mathrm{g} / \mathrm{gCr})$. Concentrations of FABP4 in plasma and urine and FABP1 in urine were measured using commercially available enzymelinked immunosorbent assay kits for FABP4 (Biovendor R\&D, Modrice, Czech Republic) and FABP1 (CIMIC Co., Tokyo, Japan). The accuracy, precision and reproducibility of the kits have been described previously [17, 24]. Levels of U-FABP4 and urinary FABP1 (U-FABP1) were normalized by urine creatinine level $(\mu \mathrm{g} / \mathrm{gCr})$.

\section{Pathological diagnosis}

Clinical classification and pathological diagnosis using kidney biopsy samples were determined by the WHO classification of kidney disease [25]. The indication for kidney biopsy was determined by the presence of proteinuria, hematuria or increased creatinine level. Minor glomerular abnormalities (MGA) were defined as the absence of histological abnormalities detectable by light microscope and immunofluorescence analyses in patients without nephrotic syndrome. Pathological diagnosis was corroborated by two pathologists.

\section{Statistical analysis}

Numeric variables are expressed as means \pm SD for normal distributions or medians (interquartile ranges) for skewed variables. The distribution of each parameter was tested for its normality using the Shapiro-Wilk W test, and non-normally distributed parameters were logarithmically transformed. Comparison between two groups was performed using Student's $t$ test for parametric parameters and the Mann-Whitney $U$ test for nonparametric parameters. One-way analysis of variance and the Tukey-Kramer post hoc test for parametric parameters and the Kruskal-Wallis test and the SteelDwass post hoc test for nonparametric parameters were used for detecting significant differences in data between multiple groups. The correlation between two variables was evaluated using Pearson's correlation coefficient. Multivariable regression analyses were performed to identify independent determinants of proteinuria, eGFR and U-FABP4 after adjustment of factors selected by stepwise regression analyses using Akaike's Information Criterion (AIC), showing the standardized regression coefficient $(\beta)$ and the percentage of variance in the object variables that the selected independent predictors explained $\left(R^{2}\right)$. Receiver operating characteristic curve analysis was performed to determine the inflection point at which the level of UFABP4 provided the most sensitive prediction of MCNS in patients who had nephrotic-range proteinuria $(\geq 3.5 \mathrm{~g} / \mathrm{gCr})$. The area under the curve (AUC) with the $95 \%$ confidence interval $(\mathrm{CI})$ was determined, and the cut-off point was obtained by the Youden index [26]. A $p$ value of less than 0.05 was considered statistically significant. All data were analyzed by using JMP 9.0.2 for Windows (SAS Institute, Cary, NC) and EZR [27].

\section{Results}

\section{Clinical characteristics of the study patients}

Clinical characteristics of the 81 patients who underwent kidney biopsy (mean age: $57 \pm 17$ years, male/female: 43/38) are shown in Table 1 . The numbers of patients with IgA nephropathy/IgA vasculitis, MGA, MCNS, MN and diabetic nephropathy (DN) were 26

Table 1 Clinical characteristics of the patients

\begin{tabular}{|c|c|}
\hline $\mathrm{n}$ & 81 \\
\hline Age, years & $57 \pm 17$ \\
\hline Male/Female & $43 / 38$ \\
\hline Body mass index & $23.5 \pm 4.2$ \\
\hline \multicolumn{2}{|l|}{ Diagnosis $^{a}$} \\
\hline IgA nephropathy/lgA vasculitis & $23 / 3(32.1)$ \\
\hline MGA & $15(18.5)$ \\
\hline MCNS & $9(11.1)$ \\
\hline Membranous nephropathy & $12(14.8)$ \\
\hline Diabetic nephropathy & $4(4.9)$ \\
\hline Others & $15(18.5)$ \\
\hline \multicolumn{2}{|l|}{ Blood pressure, $\mathrm{mmHg}$} \\
\hline Systolic & $126 \pm 21$ \\
\hline Diastolic & $73 \pm 13$ \\
\hline \multicolumn{2}{|l|}{ Laboratory data } \\
\hline Creatinine, mg/dL b & $0.84(0.68-1.22)$ \\
\hline Blood urea nitrogen, mg/dL b & $14.0(10.8-18.5)$ \\
\hline $\mathrm{eGFR}, \mathrm{mL} / \mathrm{min} / 1.73 \mathrm{~m}^{2}$ & $62 \pm 28$ \\
\hline Total cholesterol, mg/dL & $238 \pm 101$ \\
\hline Triglycerides, mg/dL b & $142(108-215)$ \\
\hline Fasting glucose, mg/dL & $94 \pm 13$ \\
\hline Plasma FABP4, ng/mL b & $20.4(13.1-33.7)$ \\
\hline \multicolumn{2}{|l|}{ Urinary data } \\
\hline Proteinuria, $\mathrm{g} / \mathrm{gCr}{ }^{b}$ & $0.92(0.25-3.77)$ \\
\hline Hematuria $^{a}$ & $48(59.3)$ \\
\hline Urinary FABP4, $\mu \mathrm{g} / \mathrm{gCr}{ }^{b}$ & $0.55(0.21-2.34)$ \\
\hline Urinary FABP $1, \mu \mathrm{g} / \mathrm{gCr}{ }^{b}$ & $6.78(1.74-20.80)$ \\
\hline
\end{tabular}

Variables are expressed as number, number (\%) ${ }^{a}$ means \pm SD or medians (interquartile ranges) ${ }^{b}$

eGFR estimated glomerular filtration rate, FABP fatty acid-binding protein, MCNS minimal change nephrotic syndrome, MGA minor

glomerular abnormalities 
(32.1\%), 15 (18.5\%), 9 (11.1\%), 12 (14.8\%) and 4 (4.9\%), respectively. Among the 12 patients with $\mathrm{MN}$, three patients had secondary MN. Pathophysiological diagnoses of the other patients included hypertensive nephrosclerosis $(n=4)$, myeloperoxidase-antineutrophil cytoplasmic antibody-associated glomerulonephritis $(n=3)$, focal segmental glomerular sclerosis $(n=2)$, diffuse mesangial proliferative glomerulonephritis $(n=2)$, diffuse endocapillary proliferative glomerulonephritis $(n=1)$, proteinase 3-myeloperoxidase-antineutrophil cytoplasmic antibody-associated glomerulonephritis $(n=1)$, membranoproliferative glomerulonephritis $(n=1)$ and tubulointerstitial nephritis $(n=1)$. Median levels of plasma FABP4 (P-FABP4), U-FABP4 and U-FABP1 were $20.4 \mathrm{ng} / \mathrm{dL}$, $0.55 \mu \mathrm{g} / \mathrm{gCr}$ and $6.78 \mu \mathrm{g} / \mathrm{gCr}$, respectively (Table 1).

\section{Associations of proteinuria, eGFR and U-FABP4 with clinical characteristics}

Logarithmically transformed $(\log )$ proteinuria was negatively correlated with eGFR and was positively correlated with age, systolic and diastolic blood pressures, total cholesterol, log triglycerides, log P-FABP4, log U-FABP4 and $\log$ U-FABP1 (Table 2). Stepwise and subsequent multivariable regression analyses using age, sex and the correlated parameters revealed that total cholesterol and $\log$ U-FABP4, but not $\log$ U-FABP1, were independent predictors of proteinuria ( $\mathrm{AIC}=211, R^{2}=0.57$ ).

eGFR was negatively correlated with age, systolic blood pressure, log triglycerides, log proteinuria, log P-FABP4, $\log$ U-FABP4 and log U-FABP1 (Table 2). Stepwise and subsequent multivariable regression analyses using age, sex and the correlated parameters showed that age, sex, log PFABP4 and $\log$ U-FABP4, but not $\log$ U-FABP1, were independent predictors of eGFR $\left(\mathrm{AIC}=591, R^{2}=0.51\right.$ ).

Log U-FABP4 was positively correlated with age, systolic and diastolic blood pressures, log triglycerides, $\log$ proteinuria, $\log$ P-FABP4 and $\log$ U-FABP1 and was negatively correlated with eGFR (Table 2). Stepwise and subsequent multivariable regression analyses using age, sex and the correlated parameters demonstrated that eGFR, log proteinuria and log U-FABP1 were independent predictors of U-FABP4 ( $\left.\mathrm{AIC}=233, R^{2}=0.55\right)$.

\section{Comparisons of renal dysfunction and urinary FABPs among glomerular kidney diseases}

There were significant differences in levels of proteinuria (Fig. 1a), eGFR (Fig. 1b) and U-FABP4 (Fig. 1c), but not in levels of U-FABP1 (Fig. 1d) and P-FABP4 (Supplementary Fig. S1), among groups of IgA nephropathy/IgA vasculitis, MGA, MCNS, MN, DN and others.

When compared with groups of MCNS $(n=9), \mathrm{MN}$ $(n=12)$ and DN $(n=4)$, which can be causes of nephrotic syndrome, there was no significant difference in levels of proteinuria (Supplementary Fig. S2A) and eGFR (Supplementary Fig. S2B) among the three groups. The level of U-FABP4 in MCNS was significantly lower than the levels in MN and DN (Supplementary Fig. S2C). There was no significant difference in the levels of $U$ FABP1 (Supplementary Fig. S2D).

Table 2 Correlation and multivariable regression analyses for proteinuria, eGFR and urinary FABP4 $(n=81)$

\begin{tabular}{|c|c|c|c|c|c|c|c|c|c|c|c|c|}
\hline & \multicolumn{4}{|c|}{ log Proteinuria } & \multicolumn{4}{|l|}{ eGFR } & \multicolumn{4}{|c|}{ log Urinary FABP4 } \\
\hline & \multicolumn{2}{|c|}{ Correlation } & \multicolumn{2}{|c|}{$\begin{array}{l}\text { Multivariable } \\
\text { regression }\end{array}$} & \multicolumn{2}{|c|}{ Correlation } & \multicolumn{2}{|c|}{$\begin{array}{l}\text { Multivariable } \\
\text { regression }\end{array}$} & \multicolumn{2}{|c|}{ Correlation } & \multicolumn{2}{|c|}{$\begin{array}{l}\text { Multivariable } \\
\text { regression }\end{array}$} \\
\hline & $r$ & $\mathbf{p}$ & $\beta$ & $\mathbf{p}$ & $r$ & $\mathbf{p}$ & $\beta$ & $\mathbf{p}$ & $r$ & $\mathbf{p}$ & $\beta$ & $\mathbf{p}$ \\
\hline Age & 0.44 & $<0.01$ & 0.14 & 0.12 & -0.63 & $<0.01$ & -0.21 & 0.02 & 0.42 & $<0.01$ & 0.07 & 0.44 \\
\hline Sex (Male) & - & - & -0.06 & 0.42 & - & - & 0.19 & 0.03 & - & - & 0.14 & 0.10 \\
\hline Body mass index & 0.19 & 0.07 & n.s. & - & -0.06 & 0.58 & - & - & -0.09 & 0.43 & - & - \\
\hline Systolic blood pressure & 0.38 & $<0.01$ & n.s. & - & -0.44 & $<0.01$ & n.s. & - & 0.43 & $<0.01$ & n.s. & - \\
\hline Diastolic blood pressure & 0.24 & 0.02 & - & - & -0.23 & 0.38 & - & - & 0.24 & 0.04 & - & - \\
\hline Total cholesterol & 0.48 & $<0.01$ & 0.38 & $<0.01$ & 0.02 & 0.83 & - & - & 0.07 & 0.53 & - & - \\
\hline log Triglycerides & 0.41 & $<0.01$ & - & - & -0.23 & 0.03 & n.s. & - & 0.28 & 0.02 & n.s. & - \\
\hline Fasting glucose & 0.04 & 0.67 & - & - & 0.01 & 0.95 & - & - & 0.08 & 0.50 & - & - \\
\hline eGFR & -0.43 & $<0.01$ & n.s. & - & - & - & - & - & -0.56 & $<0.01$ & -0.25 & 0.03 \\
\hline log Proteinuria & - & - & - & - & -0.43 & $<0.01$ & n.s. & - & 0.58 & $<0.01$ & 0.11 & 0.03 \\
\hline log Plasma FABP4 & 0.45 & $<0.01$ & n.s. & - & -0.69 & $<0.01$ & -0.34 & $<0.01$ & 0.55 & $<0.01$ & 0.20 & 0.07 \\
\hline log Urinary FABP4 & 0.53 & $<0.01$ & 0.43 & $<0.01$ & -0.56 & $<0.01$ & -0.25 & 0.04 & - & - & - & - \\
\hline \multirow[t]{2}{*}{ log Urinary FABP1 } & 0.55 & $<0.01$ & 0.24 & 0.12 & -0.48 & $<0.01$ & -0.01 & 0.94 & 0.52 & $<0.01$ & 0.28 & $<0.01$ \\
\hline & & & \multicolumn{2}{|c|}{$R^{2}=0.57$} & & & \multicolumn{2}{|c|}{$R^{2}=0.51$} & & & \multicolumn{2}{|c|}{$R^{2}=0.55$} \\
\hline
\end{tabular}



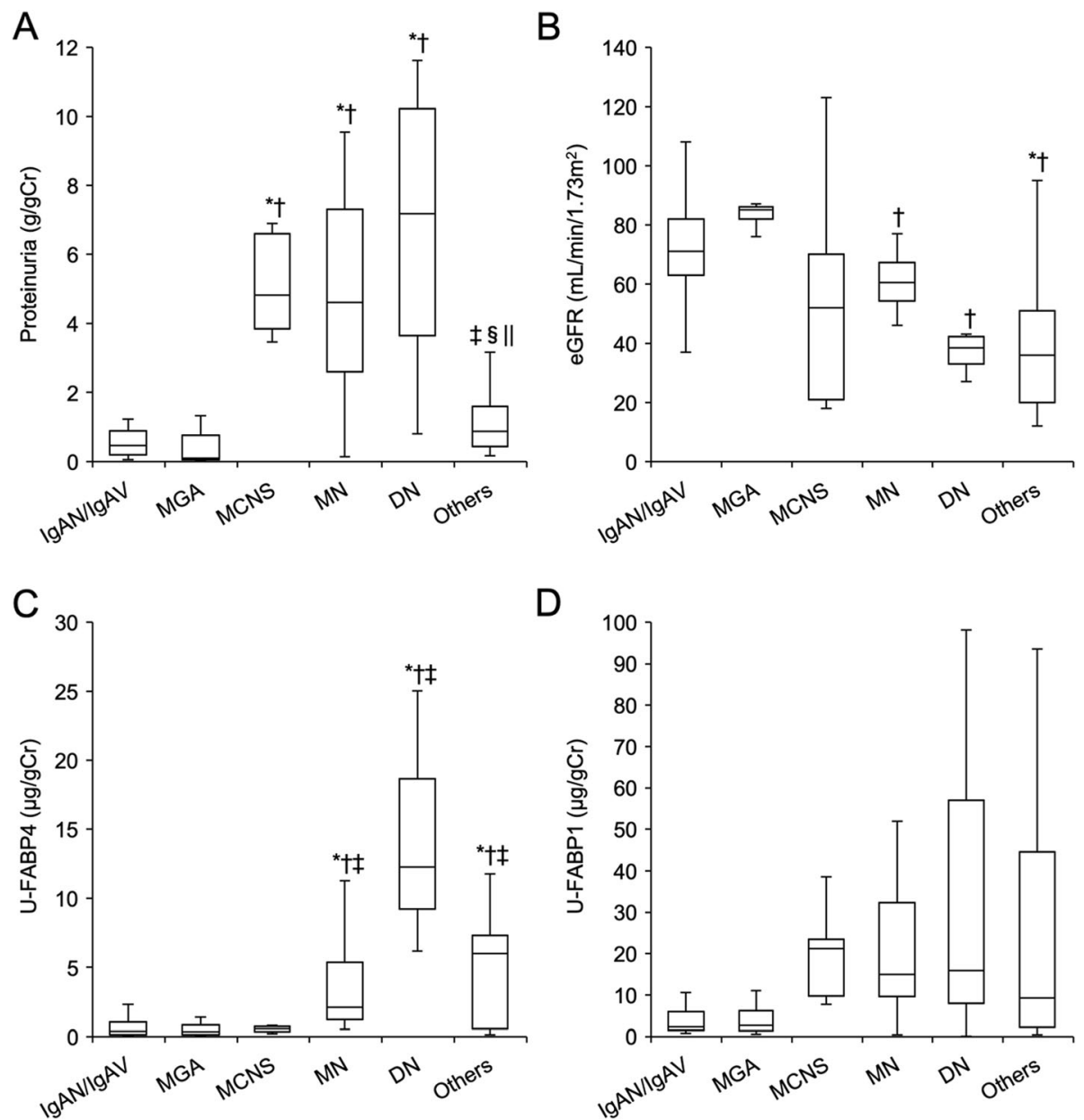

Fig. 1 Comparisons of proteinuria, renal function and urinary FABPs among kidney diseases. a-d. Comparisons of levels of proteinuria (a), estimated glomerular filtration rate (eGFR) (b), urinary fatty acid-binding protein 4 (U-FABP4) (c) and urinary fatty acid-binding protein 1 (U-FABP1) (d) in patients with IgA nephropathy/lgA vasculitis (IgAN/IgAV, $n=26)$, minor glomerular abnormalities (MGA, $n=15)$, minimal change nephrotic syndrome (MCNS, $n=9)$, membranous nephropathy $(M N, n=12)$, diabetic nephropathy $(\mathrm{DN}, n=4)$ and others $(n=15) .{ }^{*} P<0.05 \mathrm{vs}$. IgAN/lgAV, $+P<0.05$ vs. $M G A, \neq P<0.05$ vs. MCNS, $\S P<0.05$ vs. $M N, \| P<0.05$ vs. $D N$

\section{Prediction of MCNS in patients with nephrotic-range proteinuria}

In 25 patients who had nephrotic-range proteinuria $(\geq$ $3.5 \mathrm{~g} / \mathrm{gCr})$, including MCNS $(n=9), \mathrm{MN}(n=7), \mathrm{DN}$ $(n=3)$, IgA vasculitis $(n=3)$, focal segmental glomerular sclerosis $(n=2)$ and membranoproliferative glomerulonephritis $(n=1)$, the AUC of receiver operating characteristic curve analysis for U-FABP4 level to predict MCNS was 0.92, and the cut-off point of U-FABP4 level by the Youden index was $0.78 \mu \mathrm{g} / \mathrm{gCr}$ (Fig. 2), indicating that a level of U-FABP $4 \leq 0.78 \mu \mathrm{g} / \mathrm{gCr}$ predicts MCNS.

\section{Yearly changes in eGFR in the low and high groups of urinary FABPs}

Follow-up examination after 1 year in our institute (Teine Keijinkai Hospital) was performed in 33 of the 81 patients. The patients were divided into two groups by the median value of U-FABP4 or U-FABP1 at baseline: low and high groups. The yearly change in eGFR, defined as the value at one-year follow-up minus the baseline value, in the low U-FABP4 group was significantly greater than that in the high U-FABP4 group (median: 11.0 vs. $-5.0 \mathrm{~mL} / \mathrm{min} / 1.73 \mathrm{~m}^{2} /$ year) (Fig. 3a). There was no significant difference in the yearly change in eGFR between the low and high U-FABP1 groups (Fig. 3b).

\section{Discussion}

The present study demonstrated for the first time that U-FABP4 level has a significant association with renal dysfunction and prognosis in patients with biopsy-based diagnosis of kidney diseases. The level of U-FABP4 was independently associated with levels of proteinuria and eGFR in patients with kidney disease, and the association of U-FABP4 with proteinuria or eGFR was independent of circulating FABP4 and U-FABP1, which reflects damage of proximal tubular epithelial cells $[16,17]$. The level 


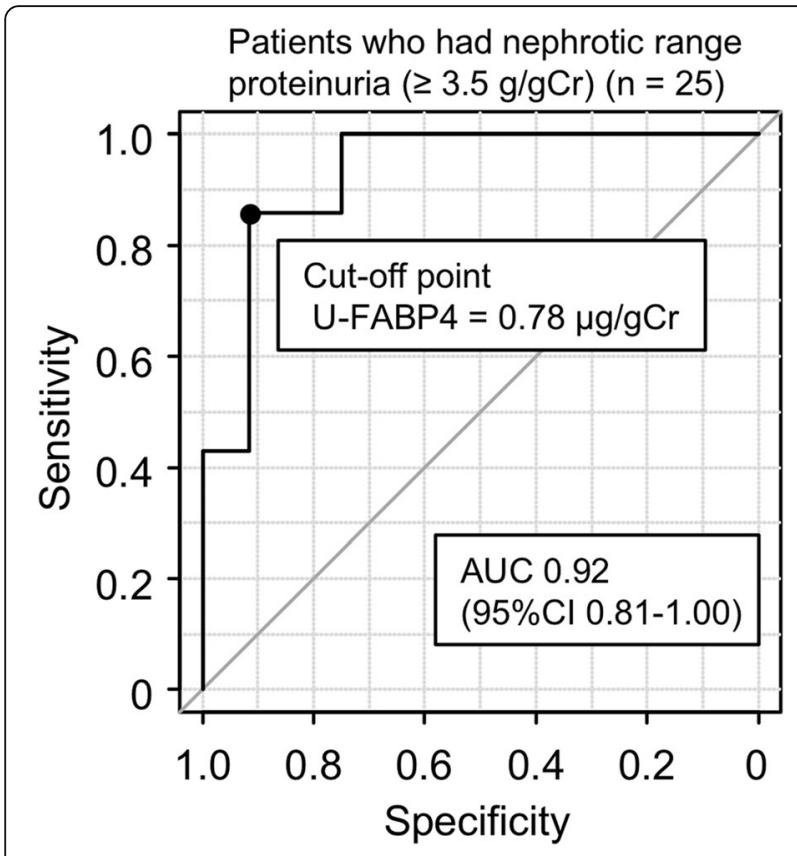

Fig. 2 Cut-off point of U-FABP4 level to predict MCNS in patients with nephrotic-range proteinuria. Receiver operating characteristic curve analysis to determine the cut-off points of urinary fatty acidbinding protein 4 (U-FABP4) level for prediction of minimal change nephrotic syndrome (MCNS) in patients who had nephrotic-range proteinuria $(\geq 3.5 \mathrm{~g} / \mathrm{gCr}, n=25)$

of U-FABP4 in MCNS was significantly lower than that in $\mathrm{MN}$ and that in $\mathrm{DN}$, and a low U-FABP4 level predicted MCNS in patients who had nephrotic-range proteinuria ( $\geq 3.5 \mathrm{~g} / \mathrm{gCr}$ ) with a high level of accuracy (AUC: 0.92). Therefore, the level of U-FABP4 would be a useful biomarker for differential diagnosis of MCNS and MN, which are common causes of nephrotic syndrome.
It has been reported that the circulating level of antiPLA2R antibodies is useful for diagnosis of idiopathic MN [7-9]. However, the sensitivity of the circulating level of anti-PLA2R antibodies for diagnosis of idiopathic $\mathrm{MN}$ was reported to be relatively low (53\%) in Japan [10] unlike in other populations in a meta-analysis (78\%) [9]. In addition, both idiopathic $\mathrm{MN}$ and secondary $\mathrm{MN}$ were included in the present study. Therefore, the level of U-FABP4 might be more useful than the level of antiPLA2R antibodies for differential diagnosis of MCNS and both idiopathic and secondary types of MN. Further studies using a large number of patients are needed to clarify the significance of U-FABP4 as a useful biomarker for differential diagnosis of MCNS and MN by comparisons of several clinical markers such as selectivity index [5], urinary podocytes [6] and PLA2R [7].

FABP4 is not expressed in vascular endothelial cells of the artery and glomerulus in a normal condition [21]. It has been reported that ectopic FABP4 expression is induced by cellular senescence and arterial vascular injury in vascular endothelial cells [13, 28, 29]. We previously showed that protein and mRNA levels of FABP4 were ectopically expressed in glomerular endothelial cells by glomerular injury [22]. The semiquantitative area of FABP4 expression in the glomerulus was positively correlated with proteinuria and was negatively correlated with the yearly change in eGFR [22]. FABP4 was thought to be a non-secreted protein since it does not have an apparent signal peptide in the amino acid sequence [12], but it has recently been shown that FABP4 is secreted from adipocytes in association with lipolysis via a nonclassical pathway [30]. We recently demonstrated that ectopically expressed FABP4 is secreted from injured vascular endothelial cells, contributing to the development of neointima formation after vascular injury [29].
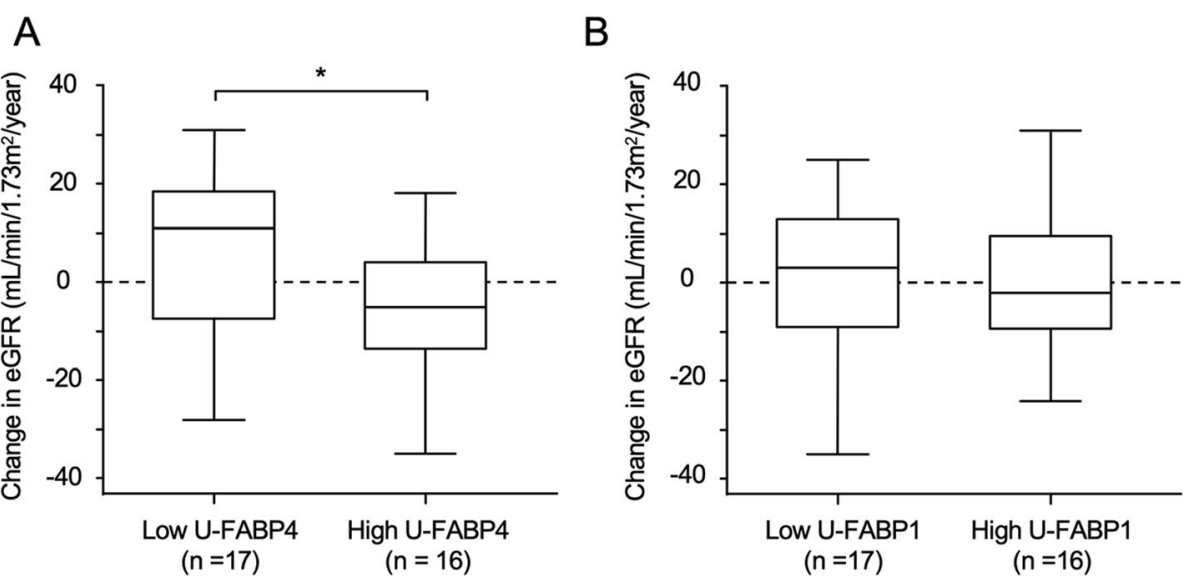

Fig. 3 Yearly declines in eGFR in low and high groups of urinary FABPs. a, b. Yearly changes (post - pre) in estimated glomerular filtration rate (eGFR) in patients ( $n=33$ ) divided by median values of urinary fatty acid-binding protein 4 (U-FABP4) $(0.72 \mu \mathrm{g} / \mathrm{gCr})(\mathbf{a})$ and urinary fatty acidbinding protein 1 (U-FABP1) $(6.77 \mu \mathrm{g} / \mathrm{gCr})(\mathbf{b}) .{ }^{*} P<0.05$ 
Similar mechanisms of local expression and secretion of FABP4 may underlie the pathogenesis in glomerular endothelial cells. Since glomerular endothelial cells have been proposed as a target for therapy to improve outcomes of kidney diseases [31], manipulation of ectopically expressed FABP4 in the glomerulus and/or a mechanism underlying urinary excretion of FABP4 could be a strategy for prevention of glomerular kidney disease.

FABP4 can pass through glomerular filtration-sized and negatively charged barriers because of its small molecular weight (about $15 \mathrm{kDa}$ ) [12] and because of the net positive surface electrostatic potential across the portal region of collisional FABPs [32, 33]. Circulating FABP4 has been reported to be processed by the kidney and reabsorbed through megalin, an endocytic receptor expressed in proximal tubule epithelial cells [34]. It has also been shown that U-FABP4 is increased before an increase in serum creatinine, clusterin or cystatin $C$ in a drug-induced glomerulonephritis model with $\mathrm{N}$ phenylanthranilic acid and puromycin in in vivo and in vitro studies [35]. Newly expressed and secreted FABP4 in the glomerulus may pass through glomerular filtration barriers, and an excess of FABP4, which exceeds the permissible amount of reabsorption in proximal tubular cells, is excreted into urine, resulting in reflection of the extent of glomerular injury.

Since levels of P-FABP4 were comparable in MCNS and $\mathrm{MN}$ in patients with nephrotic syndrome (Supplementary Fig. S1), the difference in U-FABP4 between the two groups would be attributable to new expression of FABP4 in the kidney. Crosstalk between glomerular endothelial cells and podocytes in glomerular injury has recently been highlighted [36, 37], and an association between glomerular endothelial cells and podocytes mediated by vascular endothelial growth factor (VEGF) has been suggested in patients with MN [38-41]. It has also been shown that ectopic expression of FABP4 in endothelial cells is induced by a VEGF-VEGF-receptor 2 pathway [21]. U-FABP4 derived from glomerular endothelial cells, which is possibly induced by VEGF, may affect podocytes, leading to the development of proteinuria.

It has been reported that U-FABP1 level is a marker of tubulointerstitial injury $[16,17]$ and progression of renal dysfunction in CKD patients [42, 43]. In the present study, there was no significant difference in the yearly change in eGFR between the low and high U-FABP1 groups (Fig. 3b), probably due to the small number of patients who could be followed up $(n=33)$. On the other hand, the yearly change in eGFR in the low U-FABP4 group was significantly greater than that in the high UFABP4 group (Fig. 3a). The median value of yearly change in eGFR in the low U-FABP4 group was $11.0 \mathrm{~mL} / \mathrm{min} /$ $1.73 \mathrm{~m}^{2} /$ year, whereas that in the high U-FABP4 group was $-5.0 \mathrm{~mL} / \mathrm{min} / 1.73 \mathrm{~m}^{2} /$ year, suggesting deterioration of renal function. The low U-FABP4 group may have included kidney diseases with a high rate of response to treatment such as MCNS. Thus, the findings regarding the relationship between U-FABP4 and prognosis of eGFR are preliminary findings.

The present study had several limitations. First, since the recruited subjects were only Japanese, the results of this study may not be directly extrapolated to other ethnic groups. Second, the possibility of a selection bias in the samples cannot be excluded since the study was conducted in a single facility. Third, the number of patients enrolled in the present study was small. A multicenter study with a large number of patients is needed for confirming the associations of U-FABP4 with clinical characteristics in patients with various kidney diseases. Especially, the number of patients with DN was small among patients with nephrotic-range proteinuria. Therefore, additional large-scale studies to investigate the association between U-FABP4 and DN are needed in the future. Finally, some of the drugs used for treatment, including steroids, immunosuppressive agents and reninangiotensin system inhibitors, might have affected data for the change in eGFR as unadjusted confounding factors.

\section{Conclusions}

U-FABP4 level is independently associated with proteinuria and renal dysfunction in patients with glomerular kidney disease. A low U-FABP4 level may predict MCNS in patients with nephrotic syndrome and may be a biomarker that is useful for differential diagnosis of MCNS and $\mathrm{MN}$, which are common causes of nephrotic syndrome.

\section{Supplementary Information}

Supplementary information accompanies this paper at https://doi.org/10 1186/s12882-020-02122-y.

Additional file 1: Figure S1. Comparisons of plasma FABP4 among kidney diseases. Figure S2. Comparisons of proteinuria, renal function and urinary FABPS among kidney diseases which cause nephrotic syndrome.

\section{Abbreviations}

AUC: Area under the curve; CKD: Chronic kidney disease; Cl: Confidence interval; DN: Diabetic nephropathy; eGFR: Estimated glomerular filtration rate; FABP: Fatty acid-binding protein; MCNS: Minimal change nephrotic syndrome; MGA: Minor glomerular abnormalities; MN: Membranous nephropathy; PLA2R: M-type phospholipase A2 receptor; P-FABP4: Plasma fatty acid-binding protein 4; U-FABP1: Urinary fatty acid-binding protein 1; UFABP4: Urinary fatty acid-binding protein 4

\section{Acknowledgements}

Not applicable.

\section{Authors' contributions}

MT and MF conceptualized the study design; NM, TM, HT and YG collected the clinical data; MM, AS, and YH measured biomarkers; MT, MF, MI, MK and YO analyzed the data; MT, MF and TM drafted the manuscript. All authors revised the manuscript critically for important intellectual content and approved the final version of the article. 


\section{Funding}

MT was supported by JSPS KAKENHI (Grant Numbers: 16 K09621 and 19 K08708). MF was supported by JSPS KAKENHI (Grant Numbers: 26461384, 17 K09594 and 20 K08913), MEXT Translational Research Network Program, SENS HIN Medical Research Foundation and Terumo Foundation for Life Science and Arts. The funders of this study had no role in study design; collection, analysis, and interpretation of data; writing the report; or the decision to submit the report for publication.

\section{Availability of data and materials}

The datasets used and analyzed during the current study are available from the corresponding author on reasonable request.

\section{Ethics approval and consent to participate}

All procedures performed in studies involving human participants were in accordance with the ethical standards of the institutional committee at which the studies were conducted (IRB approval numbers 28-2-58 in Sapporo Medical University and 2017-031 in Teine Keijinkai Hospital) and with the 1964 Helsinki Declaration and its later amendments or comparable ethical standards. Written informed consent was obtained from all individual participants included in the study.

\section{Consent for publication}

Not applicable.

\section{Competing interests}

The authors declare that they have no competing interests.

\section{Author details}

'Department of Cardiovascular, Renal and Metabolic Medicine, Sapporo Medical University School of Medicine, S-1, W-16, Chuo-ku, Sapporo 060-8543, Japan. Department of Nephrology, Teine Keijinkai Hospital, Sapporo, Japan. ${ }^{3}$ Hokkaido Renal Pathology Center, Sapporo, Japan.

Received: 16 June 2020 Accepted: 23 October 2020 Published online: 03 November 2020

\section{References}

1. Ruan XZ, Varghese Z, Moorhead JF. An update on the lipid nephrotoxicity hypothesis. Nat Rev Nephrol. 2009;5(12):713-21.

2. Wanner C, Tonelli M. Kidney disease: improving global outcomes lipid guideline development work group M. KDIGO clinical practice guideline for lipid management in CKD: summary of recommendation statements and clinical approach to the patient. Kidney Int. 2014;85(6):1303-9.

3. Shroff GR, Chang TI. Risk stratification and treatment of coronary disease in chronic kidney disease and end-stage kidney disease. Semin Nephrol. 2018; 38(6):582-99.

4. Zhang WR, Parikh CR. Biomarkers of acute and chronic kidney disease. Annu Rev Physiol. 2019;81:309-33.

5. Nakamura J, Nagatoya K, Fujii N, Warada A, Tokuyama A, Masuyama S, Kajimoto S, Haga R, Yamauchi A. New selectivity index calculated using protein fraction as a substitute for the conventional selectivity index. Clin Exp Nephrol. 2019;23(10):1196-201

6. Hanamura K, Tojo A, Fujita T. Urinary and glomerular podocytes in patients with chronic kidney diseases. Clin Exp Nephrol. 2014;18(1):95-103.

7. Beck LH Jr, Bonegio RG, Lambeau G, Beck DM, Powell DW, Cummins TD, Klein JB, Salant DJ. M-type phospholipase A2 receptor as target antigen in idiopathic membranous nephropathy. N Engl J Med. 2009:361(1):11-21.

8. Hofstra JM, Beck LH Jr, Beck DM, Wetzels JF, Salant DJ. Anti-phospholipase a(2) receptor antibodies correlate with clinical status in idiopathic membranous nephropathy. Clin J Am Soc Nephrol. 2011;6(6):1286-91.

9. Du Y, Li J, He F, LV Y, Liu W, Wu P, Huang J, Wei S, Gao H. The diagnosis accuracy of PLA2R-AB in the diagnosis of idiopathic membranous nephropathy: a meta-analysis. PLoS One. 2014;9(8):e104936.

10. Akiyama S, Akiyama M, Imai E, Ozaki T, Matsuo S, Maruyama S. Prevalence of anti-phospholipase A2 receptor antibodies in Japanese patients with membranous nephropathy. Clin Exp Nephrol. 2015;19(4):653-60.

11. Hebert LA, Parikh S, Prosek J, Nadasdy T, Rovin BH. Differential diagnosis of glomerular disease: a systematic and inclusive approach. Am J Nephrol. 2013;38(3):253-66
12. Furuhashi M, Hotamisligil GS. Fatty acid-binding proteins: role in metabolic diseases and potential as drug targets. Nat Rev Drug Discov. 2008;7(6):489-503.

13. Furuhashi M. Fatty acid-binding protein 4 in cardiovascular and metabolic diseases. J Atheroscler Thromb. 2019;26(3):216-32.

14. Furuhashi M, Ishimura S, Ota H, Miura T. Lipid chaperones and metabolic inflammation. Int J Inf Secur. 2011;2011:642612.

15. Furuhashi M, Saitoh S, Shimamoto K, Miura T. Fatty acid-binding protein 4 (FABP4): pathophysiological insights and potent clinical biomarker of metabolic and cardiovascular diseases. Clin Med Insights Cardiol. 2014; 8(Suppl 3):23-33.

16. Kamijo A, Kimura K, Sugaya T, Yamanouchi M, Hase H, Kaneko T, Hirata Y, Goto A, Fujita T, Omata M. Urinary free fatty acids bound to albumin aggravate tubulointerstitial damage. Kidney Int. 2002;62(5):1628-37.

17. Kamijo A, Kimura K, Sugaya T, Yamanouchi M, Hikawa A, Hirano N, Hirata Y, Goto A, Omata M. Urinary fatty acid-binding protein as a new clinical marker of the progression of chronic renal disease. J Lab Clin Med. 2004; 143(1):23-30.

18. Furuhashi M, Tuncman G, Gorgun CZ, Makowski L, Atsumi G, Vaillancourt E, Kono K, Babaev VR, Fazio S, Linton MF, et al. Treatment of diabetes and atherosclerosis by inhibiting fatty-acid-binding protein aP2. Nature. 2007; 447(7147):959-65

19. Furuhashi M, Fucho R, Gorgun CZ, Tuncman G, Cao H, Hotamisligil GS. Adipocyte/macrophage fatty acid-binding proteins contribute to metabolic deterioration through actions in both macrophages and adipocytes in mice. J Clin Invest. 2008;118(7):2640-50.

20. Furuhashi M, Fuseya T, Murata M, Hoshina K, Ishimura S, Mita T, Watanabe $Y$ Omori A, Matsumoto M, Sugaya T, et al. Local production of fatty acidbinding protein 4 in Epicardial/perivascular fat and macrophages is linked to coronary atherosclerosis. Arterioscler Thromb Vasc Biol. 2016;36(5):825-34.

21. Elmasri $H$, Karaaslan $C$, Teper $Y$, Ghelfi $E$, Weng M, Ince TA, Kozakewich $H$, Bischoff J, Cataltepe S. Fatty acid binding protein 4 is a target of VEGF and a regulator of cell proliferation in endothelial cells. FASEB J. 2009;23(11): 3865-73.

22. Tanaka M, Furuhashi M, Okazaki Y, Mita T, Fuseya T, Ohno K, Ishimura S, Yoshida H, Miura T. Ectopic expression of fatty acid-binding protein 4 in the glomerulus is associated with proteinuria and renal dysfunction. Nephron Clin Pract. 2014;128(3-4):345-51.

23. Okazaki Y, Furuhashi M, Tanaka M, Mita T, Fuseya T, Ishimura S, Watanabe $Y$, Hoshina $\mathrm{K}$, Akasaka $\mathrm{H}$, Ohnishi $\mathrm{H}$, et al. Urinary excretion of fatty acidbinding protein 4 is associated with albuminuria and renal dysfunction. PLoS One. 2014;9(12):e115429.

24. Xu A, Wang Y, Xu JY, Stejskal D, Tam S, Zhang J, Wat NM, Wong WK, Lam KS. Adipocyte fatty acid-binding protein is a plasma biomarker closely associated with obesity and metabolic syndrome. Clin Chem. 2006;52(3):405-13.

25. Churg J, Bernstein J, Glassock R. WHO monograph. Renal disease: classification and atlas of glomerular diseases. 2nd ed. Tokyo: Igaku-Shoin; 1995.

26. Schisterman EF, Perkins NJ, Liu A, Bondell H. Optimal cut-point and its corresponding Youden index to discriminate individuals using pooled blood samples. Epidemiology. 2005;16(1):73-81.

27. Kanda Y. Investigation of the freely available easy-to-use software 'EZR' for medical statistics. Bone Marrow Transplant. 2013;48(3):452-8.

28. Lee MY, Tse HF, Siu CW, Zhu SG, Man RY, Vanhoutte PM. Genomic changes in regenerated porcine coronary arterial endothelial cells. Arterioscler Thromb Vasc Biol. 2007:27(11):2443-9.

29. Fuseya T, Furuhashi M, Matsumoto M, Watanabe Y, Hoshina K, Mita T, Ishimura S, Tanaka M, Miura T. Ectopic Fatty Acid-Binding Protein 4 Expression in the Vascular Endothelium is Involved in Neointima Formation After Vascular Injury. J Am Heart Assoc. 2017;6(9).

30. Mita T, Furuhashi M, Hiramitsu S, Ishii J, Hoshina K, Ishimura S, Fuseya T, Watanabe Y, Tanaka M, Ohno K, et al. FABP4 is secreted from adipocytes by adenyl cyclase-PKA- and guanylyl cyclase-PKG-dependent lipolytic mechanisms. Obesity (Silver Spring). 2015;23(2):359-67.

31. Jourde-Chiche N, Fakhouri F, Dou L, Bellien J, Burtey S, Frimat M, Jarrot PA, Kaplanski G, Le Quintrec M, Pernin V, et al. Endothelium structure and function in kidney health and disease. Nat Rev Nephrol. 2019;15(2):87-108.

32. LiCata VJ, Bernlohr DA. Surface properties of adipocyte lipid-binding protein response to lipid binding, and comparison with homologous proteins. Proteins. 1998;33(4):577-89.

33. Storch J, McDermott L. Structural and functional analysis of fatty acidbinding proteins. J Lipid Res. 2009;50(Suppl):S126-31. 
34. Shrestha $\mathrm{S}$, Sunaga $H$, Hanaoka $H$, Yamaguchi A, Kuwahara S, Umbarawan $Y$, Nakajima K, Machida T, Murakami M, Saito A, et al. Circulating FABP4 is eliminated by the kidney via glomerular filtration followed by megalinmediated reabsorption. Sci Rep. 2018;8(1):16451.

35. Obajdin J, Cotter M, Snelling S, Dremier S, De Ron P, Fleurance R, Valentin JP. Nogueira da Costa a, Gryshkova V. fatty-acid binding protein 4 (FABP4) as a potential preclinical biomarker of drug-induced kidney injury. Toxicol Sci. 2018;166(2):441-50.

36. Fornoni A, Merscher S, Kopp JB. Lipid biology of the podocyte--new perspectives offer new opportunities. Nat Rev Nephrol. 2014;10(7):379-88.

37. Dimke H, Maezawa Y, Quaggin SE. Crosstalk in glomerular injury and repair. Curr Opin Nephrol Hypertens. 2015;24(3):231-8.

38. Honkanen EO, Teppo AM, Gronhagen-Riska C. Decreased urinary excretion of vascular endothelial growth factor in idiopathic membranous glomerulonephritis. Kidney Int. 2000;57(6):2343-9.

39. Honkanen E, von Willebrand E, Koskinen P, Teppo AM, Tornroth T, Ruutu M, Gronhagen-Riska C. Decreased expression of vascular endothelial growth factor in idiopathic membranous glomerulonephritis: relationships to clinical course. Am J Kidney Dis. 2003:42(6):1139-48.

40. Schrijvers BF, Flyvbjerg A, De Vriese AS. The role of vascular endothelial growth factor (VEGF) in renal pathophysiology. Kidney Int. 2004;65(6):2003-17.

41. Morita M, Mii A, Shimizu A, Yasuda F, Shoji J, Masuda Y, Ohashi R, Nagahama K, Kaneko T, Tsuruoka S. Glomerular endothelial cell injury and focal segmental glomerulosclerosis lesion in idiopathic membranous nephropathy. PLoS One. 2015;10(4):e0116700.

42. Kamijo-lkemori A, Sugaya T, Yasuda T, Kawata T, Ota A, Tatsunami S, Kaise R, Ishimitsu T, Tanaka Y, Kimura K. Clinical significance of urinary liver-type fatty acid-binding protein in diabetic nephropathy of type 2 diabetic patients. Diabetes Care. 2011;34(3):691-6.

43. Kamijo A, Sugaya T, Hikawa A, Yamanouchi M, Hirata Y, Ishimitsu T, Numabe A, Takagi M, Hayakawa H, Tabei F, et al. Clinical evaluation of urinary excretion of liver-type fatty acid-binding protein as a marker for the monitoring of chronic kidney disease: a multicenter trial. J Lab Clin Med. 2005;145(3):125-33.

\section{Publisher's Note}

Springer Nature remains neutral with regard to jurisdictional claims in published maps and institutional affiliations.

Ready to submit your research? Choose BMC and benefit from:

- fast, convenient online submission

- thorough peer review by experienced researchers in your field

- rapid publication on acceptance

- support for research data, including large and complex data types

- gold Open Access which fosters wider collaboration and increased citations

- maximum visibility for your research: over $100 \mathrm{M}$ website views per year

At $\mathrm{BMC}$, research is always in progress.

Learn more biomedcentral.com/submissions 